\title{
Reliability and effects of muscular pretension on isometric strength of older adults
}

\author{
Tobias Morat • Peter Preuß
}

Received: 4 February 2013 / Accepted: 11 July 2013 / Published online: 10 August 2013

(C) European Group for Research into Elderly and Physical Activity (EGREPA) 2013

\begin{abstract}
There were two objectives to this study: (a) to determine the reliability of measuring isometric maximum torque (MT) and maximum rate of torque development (MRTD) of the knee extensor and flexor muscles and (b) to assess the effects of different muscular pretensions on MT and MRTD of older adults. Maximum strength of 35 untrained healthy older adults (aged $66.9 \pm 6.6$ years; height $1.72 \pm 0.07 \mathrm{~m}$; weight $75.2 \pm 9.6 \mathrm{~kg}$ ) was measured. Strength measurement was performed with the Dr. Wolff ISO Check using a piezo-electric force transducer. MT intra-day coefficient of variation $(\mathrm{CV})$ was between 3.30 and $12.40 \%$ for both measurement sessions. Intraclass correlation coefficients (ICC) ranging from 0.71 to 0.99 showed good relative reliability. MT test-retest reliability (between sessions 1 and 2) of knee extension reached a CV between 7.10 and $9.30 \%$ and high ICC values. The measurement of the knee flexion achieved an acceptable CV (9.40\%) at $40 \%$ muscular pretension. MRTD was negatively influenced by muscular pretension $(p<0.05)$. In conclusion, MT could be measured reliably over different trials using isometric strength measurement. The test-retest reliability was acceptable at knee extension with 10 to $40 \%$ muscular pretension and with $40 \%$ muscular pretension at knee flexion. A higher muscular
\end{abstract}

Original research The authors declare that the submitted paper, data, and results have not been published anywhere before.

Authors' contributions Tobias Morat and Peter Preuss designed the research and wrote the paper. Peter Preuss created the tables and figures. Tobias Morat performed research and analyzed the data.

T. Morat $(\bowtie)$

Institute of Movement and Sport Gerontology, German Sport

University Cologne, Am Sportpark Muengersdorf 6,

50933 Cologne, Germany

e-mail: t.morat@dshs-koeln.de

P. Preuß

University Sport, University of Bonn, Bonn, Germany pretension has no impact on MT but decreases MRTD in older adults.

Keywords Aging $\cdot$ Strength measurement $\cdot$ Torque $\cdot$ Lower extremity $\cdot$ Muscular pretension

\section{Introduction}

Human muscle strength is a complex phenomenon that is determined by many factors such as age, gender, type of contraction, and the testing position during the strength measurement [21]. With increased age, sarcopenia leads to an increased strength reduction, accompanied by a decrease in the activities of daily living (ADL), resulting in one's independent life during old age placed at a higher risk [39]. Additionally, muscular strength of the lower extremities is crucial for ADL such as standing up from a chair [1]. Furthermore, a major risk factor for falls is found in reduced strength in these muscles $[8,15,19,22,28,29]$ therefore, having strong thigh muscles contributes to fall prevention $[1$, $25,30]$.

Many older adults are unaware of the extent of strength loss in their leg muscles and the associated consequences. Although $77 \%$ of older adults correctly estimated their strength, there was an overestimation in comparison to their actual measured strength values [27]. To evaluate the strength level of older adults, suitable methods which provide meaningful and reliable values for strength measurements of leg muscles are required [36]. Besides isokinetic methods, isometric dynamometry is one of the preferred methods for the assessment of neuromuscular function in sports science. In addition to measuring maximum strength, the explosive strength or rate of force development, should also be considered [17].

Most studies measuring isometric strength have only considered the anterior (knee extensors) muscles of the thigh [4, 
14, 18, 27, 34, 35]. However, for maintaining dynamic stability, both flexors and extensors are essential and should be considered in measurements. Through the interaction of knee flexors and extensors, the center of gravity could be kept in the area of support, e.g., while standing up from a chair, walking, or in the recovery from stumbling; and falls could be avoided [7, 9, 12, 20, 24, 30]. Studies regarding isometric strength of knee extensors often measured the dominant leg [4, 9, 21, 25, 32], or both legs individually $[9,30]$. Therefore, this investigation measured isometric maximum torque (MT) and maximum rate of torque development (MRTD) of the knee extensors and flexors in bilateral contractions. Earlier studies demonstrated the reliability of isometric MT and MRTD in different measurement constructions [2, 9, 31-33, 36, 38].

The primary objective of this study was to determine the reliability of measuring MT and MRTD of the knee extensor and flexor muscles of older adults in the Dr. Wolff ISO Check (seated measurement chair to assess isometric strength; see Methods). The second aim was to investigate the influence of different levels of muscular pretension on MT and MRTD. The muscular pretension seems to have strong influence on strength measurement (MT; MRTD). Considering the literature, there are few studies focusing on this area and therefore recommendations concerning the optimal level of pretension for strength measurement, especially in older adults $[5,35]$ is limited. Viitasalo [35] examined 13 healthy male physical education students with a mean age of 21.5 years measuring isometric one-leg strength with different muscular pretension levels $(20-70 \%$ of maximum voluntary contraction). The results demonstrated a small but significant decrease in the effect on the maximal isometric strength. However, there was a greater consequence on the rate of force production. The rate of force production decreased as a function of pretension level [35]. From a physiological point of view, there are two explanations which are possible. The first possibility is to reach a higher muscular pretension one increases the number of recruited motor units and their firing frequency [35]. At low muscular pretension especially slow motor units are firing, preserving fast motor units. The latter can be used to complete a maximum rate of force or torque development. With the rise in muscular pretension, the fast motor units are already utilized to a greater extent in the maintenance of muscular pretension and finally not available for force generation [35]. The second possibility is the performance and work of the contractile component and the muscle tendon complex (MTC) which could decrease muscular pretension gradually [37].

Based on the evidence presented, there are no results concerning the effects of different muscular pretensions during isometric strength measurement in older adults. From a functional perspective, a bilateral measurement and the inclusion of knee flexors and extensors should be pursued in this target group.

\section{Methods}

The study was conducted in a test-retest design in two test sessions at an interval of 1 week on the same week day in spring of that year. Participants were instructed to maintain their usual behavior in regards to nutrition, hydration, and physical activity throughout the duration of the study. To minimize circadian variations in muscular strength, each participant was measured at the same time of the day. For test reliability, the test procedure and researcher were identical on both dates. The study protocol was approved by the ethics committee of the German Sport University Cologne.

\section{Participants}

The untrained (doing less than 2-h systematic sports per week) participants $(N=35,21$ men and 14 women) mean ( \pm SD) values for age, body height and body mass were $66.9 \pm 6.6$ years, $1.72 \pm 0.07 \mathrm{~m}$, and $75.2 \pm 9.6 \mathrm{~kg}$, respectively. Before executing the assessment, each participant completed a health questionnaire and submitted a medical clearance certificate. The exclusion criteria included severe heart, respiratory, renal or hepatic problems, advanced osteoporosis, unstable diabetes, neurological diseases, and hypertension. Informed consent was granted by each participant once all of the procedures were explained. All performance data were anonymized before analysis.

Based on the results from previous research [35], an a priori analysis estimated for MT with a sample of 24 participants was required to detect a size effect of 0.31 , with a power of 0.95 and an alpha of $<0.05$ for two sessions and four measurements $(F(3.66)=2.74)$. For MRTD a sample of four participants was required for a size effect of 1.62 , with a power of 0.99 , an alpha $<0.05$ for two sessions and four measurements $(F(3.6)=4.75)$. Power analyses were performed with the software GPower (GPower, v.3.0.10, University of Düsseldorf, Germany).

\section{Procedures}

Strength measurement was measured via Dr. Wolff ISO Check (DigiMax, Hamm, Germany) using a piezo-electric force transducer (sample rate $100 \mathrm{~Hz}$, measurement error $\pm 0.5 \%$ ). The raw torque time curve (in newton meters) was presented as online feedback via the accompanying software DigiMax. There was a monitor installed on which the participants could see the required muscular pretension for strength measurement. 
At the first test session, the strength measurement equipment was adjusted to each participant's body height. Strength was tested in a seated-position with a hip angle of $90^{\circ}$ and a knee flexion angle of $60^{\circ}[12,21,30,32,40]$, relative to $0^{\circ}$ at full knee and hip extension (see Fig. 1).

The warm-up on the cycle ergometer consisted of $10 \mathrm{~min}$ at $1.0 \mathrm{~W} / \mathrm{kg}$ body weight at a self-selected speed. Participants had three submaximal warm-up and familiarization trials with a minimum muscular pretension $(<5 \%)$. A maximal voluntary contraction (MVC) trial with a minimal pretension (reference MVC) was used to calculate the different muscular pretensions (PT) of 10, 20, 30, and $40 \%$ (PT10, PT20, PT30, PT40) of the MVC. Two trials were conducted for every muscular pretension and resulted in 24 trials per participant. Each trial lasted approximately 2 to $3 \mathrm{~s}$. A rest period between the single trials was $60 \mathrm{~s}$ and 5 min between the knee flexor and extensor tests. The participants were instructed to press as fast and as strong as possible on the researcher's signal "go" against the pad. There was no verbal encouragement during the measurement. To minimize a learning effect, participants completed the muscular pretension tests and the knee movements (extension and flexion) in a randomized order in the first session. An identical test sequence was followed in the second session (see Fig. 2). The data noise was filtered by using an adaptive Butterworth low-pass digital filter [22, 41].

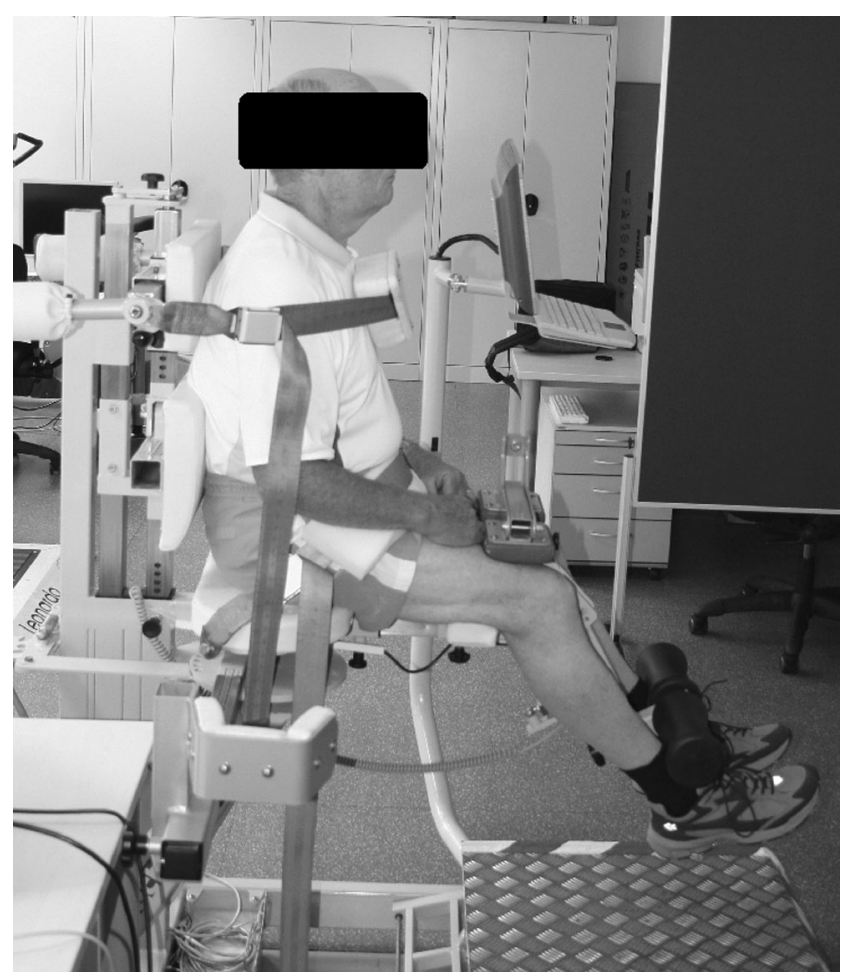

Fig. 1 Participant placed in the Dr. Wolff ISO Check for knee extension measurement
The initiation of torque increase was defined as the point at which each torque value increased (delta $=0.01 \mathrm{~N} \mathrm{~m} \mathrm{~s}^{-1}$ ) over the following 15 consecutive time points. Maximum torque (MT: in newton meters) was determined by the peak value of the torque time curve. The maximum rate of torque development (MRTD: in newton meters per second; see Fig. 3) was computed by differentiating the torque time curve and determining the maximum slope of the curve $[17,36]$. When comparing data between the two sessions (reliability and influence of pretension), the average value of the two trials per condition was used. Additionally, the average was also recorded from the two trials within each day, for analysis.

\section{Statistical analysis}

The examination of normal distribution was carried out with the D'Agostino-Pearson Test in medCalc (medCalc v10.4.8.0, Mariakerke, Belgium). An Excel Spreadsheet (Excel 2007, Microsoft, Redmond, USA) was used to test the reliability (see Table 1) between the two trials and between the two sessions [3, 10, 11, 13].

IBM SPSS Statistics 21.0 for Windows (International Business Machines Corporation, Armonk, NY, USA) was used for calculation of correlation coefficients and further statistical analysis. An ANOVA with repeated measures, with Greenhouse-Geisser correction, was conducted to assess whether there were differences between the different levels of pretension $(10,20,30,40 \%)$ within and between test sessions. If significant within-subject effects existed, the estimated marginal means were used to identify the significant differences. An alpha $<0.05$ was considered statistically significant and an alpha $<0.10$ as indicative of a trend.

\section{Results \\ Reliability}

Trial-to-trial reliability of MT knee extension in sessions one and two, mean difference $(<4 \%)$, coefficient of variation $(<6 \%)$, and effect size $(<0.14)$ were low (see Table 2$)$. Intraclass correlation coefficient $(>0.97)$ and Spearman's correlation coefficient $(>0.94)$ were high. Between both sessions, mean difference $(<11 \%)$, coefficient of variation $(<10 \%)$, and effect size $(<0.26)$ were slightly higher compared to trial-totrial, intraclass correlation coefficient $(>0.93)$ and Spearman's correlation coefficient $(>0.87)$ revealed lower values.

The trial-to-trial reliability values for MT knee flexion in sessions one and two showed a mean difference $(<7 \%)$, coefficient of variation $(<8 \%$, except session $2 \mathrm{PT} 10,12 \%)$, and effect size $(<0.10)$. The intraclass correlation coefficient $(>0.93)$ and Spearman's correlation coefficient $(>0.92)$ were 
Fig. 2 Procedure: the two sessions with the trials at each session session 1

knee extension
3 familiarization trials
1 MVC trial
2 trials per pretension
$(10 \%, 20 \%, 30 \%, 40 \%$ MVC $)$
in randomized order with $60 \mathrm{sec}$ rest
$\rightarrow$ overall 12 trials
5 minutes rest
knee flexion
3 familiarization trials
$1 \mathrm{MVC}$ trial
2 trials per pretension
$(10 \%, 20 \%, 30 \%, 40 \%$ MVC $)$
in randomized order with 60 sec rest

total 24 trials session 2

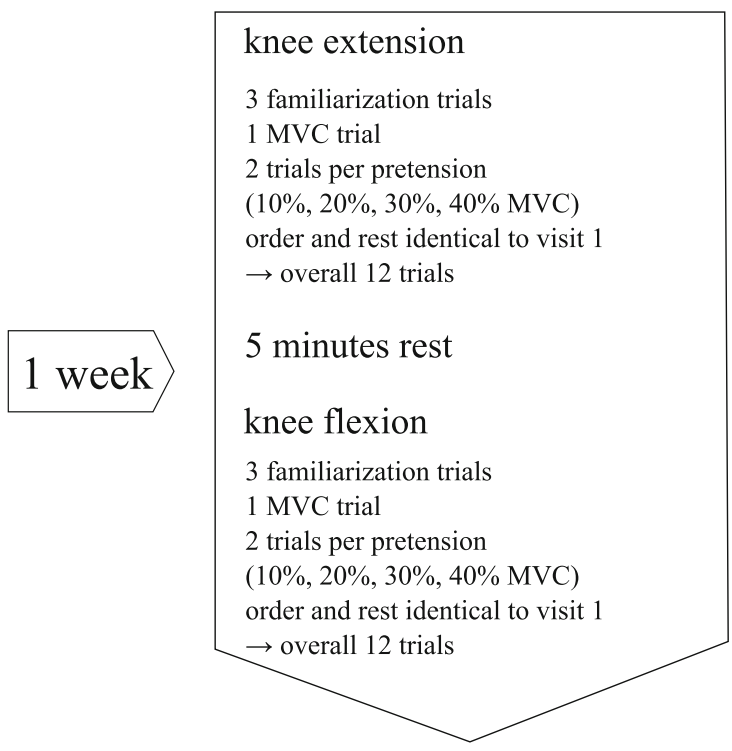

total 24 trials high. Between both sessions, the mean difference and coefficient of variation declined with increasing pretension. The effect size (0.04-0.18) was slightly higher for trial-to-trial, the intraclass correlation coefficient $(>0.84)$ and Spearman's correlation coefficient $(>0.89)$ lower than that for knee extension.

Concerning the same aspects of reliability for MRTD, there was a similar trend but with a higher coefficient of variation and mean difference and a lower intraclass correlation coefficient and Spearman's correlation coefficient for MT.

\section{Pretension}

MT for knee extension showed higher values with increasing pretension at both sessions (see Table 3). Figure 3 illustrates
Fig. 3 Graphical illustration and the equation for calculating the slope of the torque time curve (MT maximum torque; MRTD maximum rate of torque development)

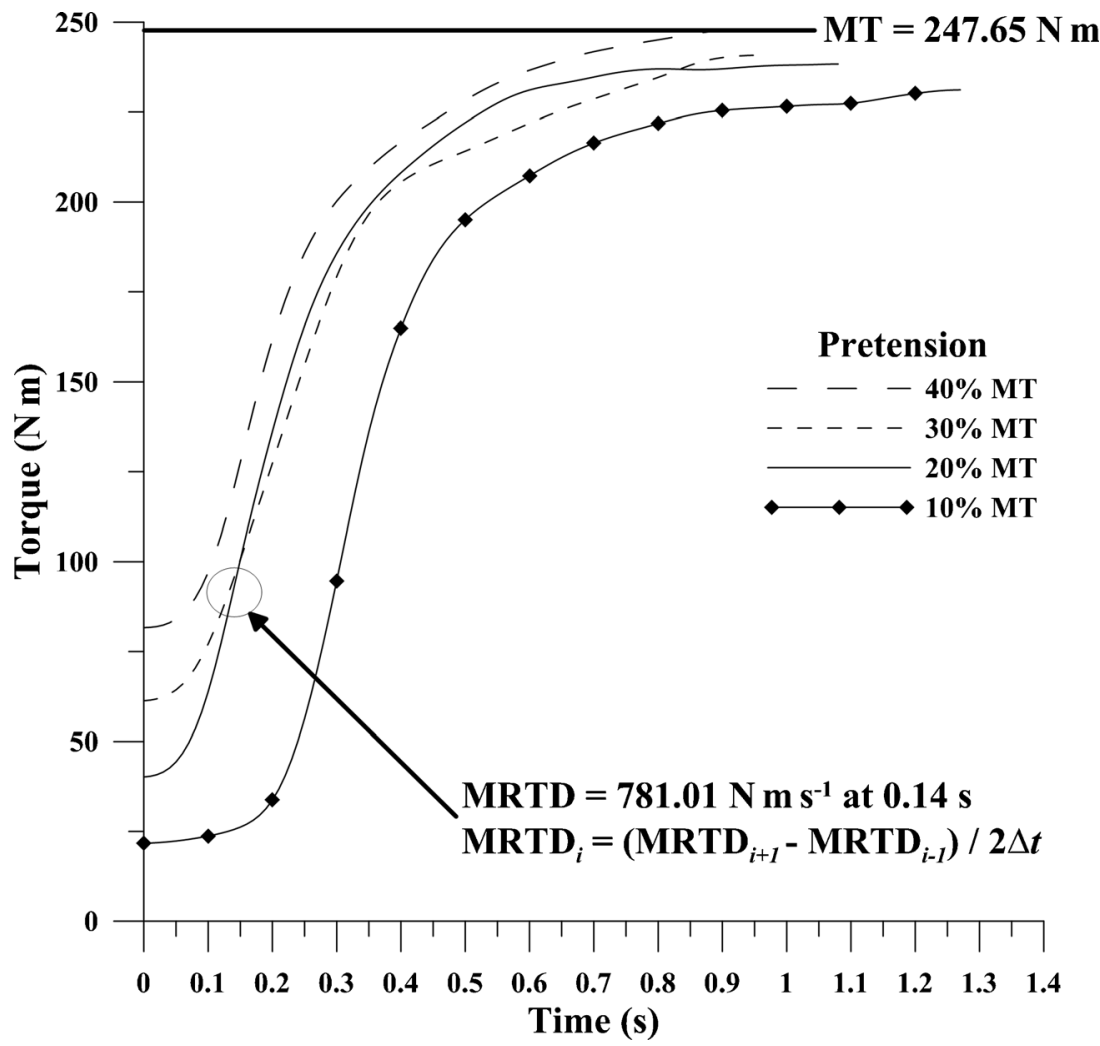


Table 1 Reliability statistics between the two related trials and between the two sessions

Measures of

reliability statistics

\begin{tabular}{ll}
\hline Absolute reliability & $\begin{array}{l}\text { Mean difference }(M D) \\
\text { Coefficient of variation }(C V)\end{array}$ \\
Stability & Intraclass correlation coefficient $\left(I C C_{r}\right)$ \\
& Effect size $(d)$ \\
Relative reliability & Spearman's correlation coefficient $\left(r_{s}\right)$ \\
\hline
\end{tabular}

an example of one of the participants from the study of the different strength time curves.

Repeated measures analysis of variance performed on the data revealed significant differences between the two sessions $\left(\mathrm{F}(1,34)=27.189, p<0.001, \eta^{2}=0.444\right)$ and between the different pretensions $(\mathrm{F}(2.308,78.484)=4.716, p=0.009$, $\eta^{2}=0.122$ ). MT in knee flexion demonstrated a slightly different characteristic in comparison to knee extension. There were significant differences between sessions $(\mathrm{F}(1,34)=8.666$, $\left.p=0.006, \eta^{2}=0.203\right)$ and no differences between the different pretensions $\left(\mathrm{F}(2.253,76.604)=1.939, p=0.128, \eta^{2}=0.054\right)$.

MRTD for increasing pretension were lower. There were no significant differences for knee extension between sessions $\left(\mathrm{F}(1,34)<1, p=0.926, \eta^{2}<0.001\right)$ but for different pretensions $\left(\mathrm{F}(1.715,58.297)=15.967, p<0.001, \eta^{2}=0.320\right)$. MRTD for knee flexion showed the same trend as knee extension i.e., lower MRTD with higher pretension, apart from PT10 to PT20 for the first session. Repeated measures analysis of variance on the four pretension levels revealed significant differences between the sessions $\left(\mathrm{F}(1,34)=7.405, p=0.010, \eta^{2}=0.179\right)$ and between different pretensions $(\mathrm{F}(2.306,78.418)=6.372$, $\left.p=0.002, \eta^{2}=0.158\right)$.

Table 2 Reliability statistics for strength measures (maximum torque (MT [N m]) and maximum rate of torque development (MRTD [N m s$\left.{ }^{-1}\right]$ ), $n=35)$ obtained for knee extension and flexion during the two trials at the same session $(\operatorname{tr} 1, \operatorname{tr} 2)$ and the two test sessions (s1, s2)

\begin{tabular}{|c|c|c|c|c|c|c|c|c|c|c|c|c|c|c|c|c|}
\hline \multirow[b]{2}{*}{ Comparison } & \multirow[b]{2}{*}{ Variable } & \multirow[b]{2}{*}{ PT } & \multicolumn{7}{|c|}{ Extension } & \multicolumn{7}{|l|}{ Flexion } \\
\hline & & & $\mathrm{MD}[\%]$ & CV [\%] & SMD & SEM & $\mathrm{ICC}^{\diamond}$ & $d$ & $\mathrm{r}_{\mathrm{s}}^{\diamond}$ & MD [\%] & $\mathrm{CV}[\%]$ & SMD & SEM & $\mathrm{ICC}^{\ominus}$ & d & $\mathrm{r}_{\mathrm{s}}^{\diamond}$ \\
\hline \multirow[t]{8}{*}{$\mathrm{s} 1: \operatorname{tr} 1-\operatorname{tr} 2$} & \multirow[t]{4}{*}{$\mathrm{MT}[\mathrm{N} \mathrm{m}]$} & 10 & 2.30 & 3.30 & 0.06 & 0.09 & 0.99 & 0.06 & 0.99 & 6.30 & 7.90 & 0.11 & 0.14 & 0.98 & 0.09 & 0.98 \\
\hline & & 20 & 2.90 & 5.40 & 0.08 & 0.15 & 0.98 & 0.08 & 0.98 & 2.50 & 7.20 & 0.05 & 0.13 & 0.99 & 0.02 & 0.97 \\
\hline & & 30 & 1.60 & 5.10 & 0.05 & 0.15 & 0.98 & 0.06 & 0.95 & 3.70 & 5.80 & 0.08 & 0.12 & 0.99 & 0.06 & 0.97 \\
\hline & & 40 & 3.70 & 4.40 & 0.12 & 0.14 & 0.98 & 0.13 & 0.97 & 1.90 & 4.80 & 0.05 & 0.11 & 0.99 & 0.04 & 0.97 \\
\hline & \multirow[t]{4}{*}{$\operatorname{MRTD}\left[\mathrm{N} \mathrm{m} \mathrm{s}^{-1}\right]$} & 10 & 2.50 & 19.30 & 0.05 & 0.34 & 0.90 & 0.04 & 0.90 & 6.10 & 19.70 & 0.08 & 0.23 & 0.95 & 0.08 & 0.95 \\
\hline & & 20 & 12.20 & 29.00 & 0.22 & 0.49 & 0.82 & 0.23 & 0.85 & 5.50 & 21.70 & 0.07 & 0.24 & 0.95 & 0.11 & 0.97 \\
\hline & & 30 & -0.30 & 22.60 & -0.01 & 0.38 & 0.89 & 0.08 & 0.90 & 5.80 & 15.40 & 0.07 & 0.18 & 0.97 & 0.10 & 0.95 \\
\hline & & 40 & 0.90 & 30.10 & 0.02 & 0.54 & 0.79 & 0.04 & 0.79 & 1.90 & 29.40 & 0.03 & 0.43 & 0.86 & 0.05 & 0.85 \\
\hline \multirow[t]{8}{*}{$\mathrm{s} 2: \operatorname{tr} 1-\operatorname{tr} 2$} & \multirow[t]{4}{*}{$\mathrm{MT}[\mathrm{N} \mathrm{m}]$} & 10 & 1.40 & 4.70 & 0.04 & 0.13 & 0.98 & 0.04 & 0.97 & -0.50 & 12.40 & -0.01 & 0.28 & 0.93 & 0.03 & 0.97 \\
\hline & & 20 & 0.90 & 5.20 & 0.03 & 0.16 & 0.98 & 0.01 & 0.95 & 2.90 & 6.00 & 0.07 & 0.14 & 0.98 & 0.06 & 0.98 \\
\hline & & 30 & 1.80 & 5.00 & 0.06 & 0.16 & 0.98 & 0.08 & 0.97 & 0.70 & 5.30 & 0.02 & 0.13 & 0.98 & 0.02 & 0.97 \\
\hline & & 40 & 0.00 & 4.40 & 0.00 & 0.14 & 0.98 & 0.01 & 0.98 & 0.60 & 4.80 & 0.02 & 0.12 & 0.99 & 0.03 & 0.98 \\
\hline & \multirow[t]{4}{*}{ MRTD [ $\left.\mathrm{N} \mathrm{m} \mathrm{s}^{-1}\right]$} & 10 & 8.00 & 13.70 & 0.15 & 0.25 & 0.95 & 0.16 & 0.94 & -4.10 & 19.10 & -0.06 & 0.27 & 0.94 & 0.04 & 0.95 \\
\hline & & 20 & 4.90 & 18.30 & 0.09 & 0.33 & 0.91 & 0.11 & 0.88 & 5.60 & 18.50 & 0.07 & 0.23 & 0.95 & 0.03 & 0.94 \\
\hline & & 30 & -4.70 & 16.90 & -0.10 & 0.32 & 0.91 & 0.02 & 0.90 & 0.30 & 17.40 & 0.00 & 0.23 & 0.95 & 0.02 & 0.95 \\
\hline & & 40 & -2.70 & 19.40 & -0.05 & 0.33 & 0.91 & 0.11 & 0.87 & 4.70 & 18.00 & 0.07 & 0.25 & 0.95 & 0.09 & 0.93 \\
\hline \multirow[t]{8}{*}{$\mathrm{s} 1-\mathrm{s} 2$} & \multirow[t]{4}{*}{$\mathrm{MT}[\mathrm{N} \mathrm{m}]$} & 10 & 10.00 & 9.30 & 0.27 & 0.25 & 0.94 & 0.24 & 0.94 & 12.90 & 17.60 & 0.18 & 0.25 & 0.94 & 0.18 & 0.94 \\
\hline & & 20 & 8.00 & 7.40 & 0.23 & 0.22 & 0.96 & 0.20 & 0.92 & 12.10 & 20.60 & 0.26 & 0.43 & 0.85 & 0.16 & 0.92 \\
\hline & & 30 & 8.80 & 8.00 & 0.27 & 0.25 & 0.95 & 0.25 & 0.88 & 8.00 & 18.90 & 0.19 & 0.44 & 0.85 & 0.15 & 0.90 \\
\hline & & 40 & 6.10 & 7.10 & 0.20 & 0.23 & 0.95 & 0.20 & 0.93 & 2.60 & 9.40 & 0.07 & 0.23 & 0.95 & 0.04 & 0.96 \\
\hline & \multirow[t]{4}{*}{ MRTD [ $\mathrm{N} \mathrm{m} \mathrm{s}^{-1}$ ] } & 10 & -7.90 & 22.50 & -0.17 & 0.42 & 0.86 & 0.15 & 0.86 & 24.10 & 30.00 & 0.32 & 0.40 & 0.87 & 0.24 & 0.86 \\
\hline & & 20 & 2.20 & 18.00 & 0.04 & 0.34 & 0.91 & 0.04 & 0.88 & 11.30 & 31.90 & 0.15 & 0.39 & 0.88 & 0.07 & 0.91 \\
\hline & & 30 & 5.60 & 29.80 & 0.12 & 0.58 & 0.76 & 0.04 & 0.80 & 15.50 & 41.30 & 0.22 & 0.52 & 0.80 & 0.18 & 0.87 \\
\hline & & 40 & 1.10 & 26.00 & 0.02 & 0.49 & 0.81 & 0.08 & 0.82 & 18.10 & 30.70 & 0.28 & 0.45 & 0.84 & 0.26 & 0.88 \\
\hline
\end{tabular}

$s 1$ session 1; $s 2$ session 2; $\operatorname{tr} 1$ trial 1; tr2 trial 2; $M T$ maximum torque; MRTD maximum rate of torque development; $P T$ pretension; $M D$ mean difference; $C V$ coefficient of variation; SDM standardized mean difference; SEM standard error of measurement; ICC intraclass correlation coefficient; $d$ effect size; $r_{s}$ Spearman's correlation coefficient

${ }^{\diamond}$ Significant correlations $(p<0.05)$ 
Table 3 Maximum torque (MT $[\mathrm{N} \mathrm{m}]$ ) and maximum rate or torque development (MRTD, $\left[\mathrm{N} \mathrm{m} \mathrm{s}^{-1}\right]$ ) at different muscular pretensions (PT10, PT20, PT30, PT40) of knee extension and flexion at and between sessions 1 and $2(\mathrm{M} \pm \mathrm{SD}), n=35$ and the differences between pretensions and sessions

\begin{tabular}{|c|c|c|c|c|c|c|c|}
\hline Movement & Variable & Session & PT10 & PT20 & PT30 & PT40 & Significant differences \\
\hline \multirow[t]{4}{*}{ Knee extension } & $\mathrm{MT}[\mathrm{N} \mathrm{m}]$ & 1 & $191.8 \pm 70.2$ & $196.6 \pm 68.8$ & $197.7 \pm 62.8$ & $201.8 \pm 60.4$ & PT10 to PT20, 30, $40(p<0.05)$ \\
\hline & & 2 & $208.9 \pm 70.0^{\diamond}$ & $210.6 \pm 67.5^{\diamond}$ & $213.6 \pm 61.5^{\diamond}$ & $214.4 \pm 64.4^{\diamond}$ & PT10 to PT40 $(p<0.05)$ \\
\hline & MRTD $\left[\mathrm{N} \mathrm{m} \mathrm{s}^{-1}\right]$ & 1 & $904.9 \pm 464.9$ & $793.4 \pm 415.6$ & $707.1 \pm 383.8$ & $694.6 \pm 318.2$ & PT10 to PT20, 30, 40 and PT20 to PT30, $40(p<0.05)$ \\
\hline & & 2 & $836.5 \pm 448.8$ & $811.2 \pm 425.0$ & $721.8 \pm 333.7$ & $720.1 \pm 349.0$ & PT10 to PT30, 40 and PT20 to PT $30,40(p<0.05)$ \\
\hline \multirow[t]{4}{*}{ Knee flexion } & $\mathrm{MT}[\mathrm{N} \mathrm{m}]$ & 1 & $172.8 \pm 77.5$ & $175.9 \pm 79.0$ & $175.9 \pm 70.0$ & $185.0 \pm 69.8$ & - \\
\hline & & 2 & $185.7 \pm 66.4^{\diamond}$ & $187.5 \pm 68.1^{\diamond}$ & $185.9 \pm 68.3^{\diamond}$ & $188.1 \pm 67.2$ & - \\
\hline & $\operatorname{MRTD}\left[\mathrm{N} \mathrm{m} \mathrm{s}{ }^{-1}\right]$ & 1 & $564.8 \pm 369.8$ & $586.5 \pm 404.6$ & $520.0 \pm 323.3$ & $467.6 \pm 302.5$ & $\begin{array}{l}\text { PT10, 20, } 30 \text { to PT40 }(p<0.05) \\
\text { PT20 to PT30 }(p<0.05)\end{array}$ \\
\hline & & 2 & $656.2 \pm 388.9^{\diamond}$ & $616.7 \pm 402.5$ & $581.7 \pm 361.3$ & $550.3 \pm 325.6^{\diamond}$ & PT10, 20 to PT40 $(p<0.05)$ \\
\hline
\end{tabular}

$P T$ pretension

${ }^{\diamond}$ Significant difference between sessions 1 and $2(p<0.05)$

MT maximum torque; MRTD maximum rate of torque development

\section{Discussion}

\section{Reliability}

The stability between the tests (intraclass correlation coefficient (ICC)) showed good reliability for the knee flexors, MT, and MRTD in both sessions, except for PT20, PT30, and PT40. Test-retest stability between the sessions showed ICC values of 0.76 and 0.96 for the knee flexors and extensors. These results are in accordance with past studies [9, 31-33, $36,38]$. Other studies of the stability of measurement, i.e., effect size, highlight the reproducibility of measurements is consistent during a specific session but not between the sessions. It is suggested, if reliability is to be considered, and then the ICC, MT and MRTD values should be reliable [6]. Spearman's correlation coefficient (0.80-0.96) supports a good relative reliability of measurement.

With respect to absolute reliability (coefficient of variation $(\mathrm{CV})<10 \%$ ) between the individual trials, only the MT in the knee flexors (except PT10) and MT in the knee extensors in both sessions could be measured reliably. For the absolute test-retest reliability between the sessions, only the MT in the knee flexors, at PT40 and with all muscular pretensions in the knee extensors, is reliable. In contrast to previous studies [32, 36, 38], the high coefficient of variation $(>10 \%)$ of the present study displays poor absolute reliability. The different knee angles could have lead to a more reliable measurement in knee flexion [38]. This facet could be investigated in future studies by comparing different knee flexion angles and the measurement reliability. Existing controversial opinions to the measuring of reliability will be challenging based on the notion of defining the specific criteria of reliability in sports science [3].
In comparison, the strength values in the second session were higher than those in the first session. These observations were confirmed by earlier studies $[21,33]$. Despite the consistency of the controllable factors, the authors speculate that there was learning or practice effect after the first session [3]. An additional session of "familiarization" prior to the "real" measurement may mitigate a possible learning effect and measurement error.

Hopkins et al. suggest a sample size of $N=50$ for reliability studies for an accurate measurement of reliability [10]. Therefore, a further question should be considered; which focuses on the suitable approach should be taken to ensure the testing economy and participant retention. A comparison of the number of testing sessions required to achieve one repetition maximum (1RM) strength measurements in six participants displayed a requirement of eight to nine testing sessions by older adults [26]. An additional study concluded that three familiarization sessions and two to three test trials produced reliable 1RM measures [23]. For isometric strength testing, there are fewer studies reporting this issue. However, in isometric strength testing, the coordinative aspects do not have such a meaningful impact on the measurements. Subsequently, there is no certainty that a single, or several, familiarization sessions would make any difference [16]. Therefore, further investigations are required to substantiate this theory. Nevertheless, in intervention studies, practitioners have to find a balance between systematic errors and testing effort.

In conclusion, MT could be measured reliably over different trials using isometric strength measurement. The testretest reliability was acceptable at knee extension with 10 to $40 \%$ muscular pretension and with $40 \%$ muscular pretension at knee flexion. 


\section{Pretension}

As hypothesized, there was a significant influence of muscular pretension on MRTD. The assumption that the MRTD decreases with increasing muscular pretension was confirmed [35]. In this study, a higher pretension corresponded to a lower MRTD. From a physiological point of view, two explanations were identified. The first explanation is, if one has a higher muscular pretension, a larger amount of fast motor units are recruited with an increase in their firing frequency [35]. In contrast, during low muscular pretension, slow motor units are activated; fast motor units are preserved to generate a larger maximum strength [35].

The second reason is the performance and work of the muscular contractile and tendon complex (MTC) which gradually decreased through muscular pretension [37]. Therefore, the results for MT showed no differences at different muscular pretensions in the measurement of isometric knee extensors and flexors in older adults.

An optimal pretension could also be relevant for older adults during power training. To prevent injuries, a minimum muscular pretension could help to guarantee muscular protection of the joints. As the results in this study have shown, the muscular pretension should be minimal to achieve a high rate of torque development. Furthermore, after stumbling, for example, a maximum rate of force development is more important than the maximum force.

Regarding the influence of muscular pretension on maximum isometric and explosive strength, there are very few results, especially when relating to older adults.

\section{Conclusions}

This study has identified the maximum knee extension and flexion torque (MT) showed reliable trial-to-trial measurements. With this in mind, good test-retest reliability (between the two sessions) can be assumed with all muscular pretensions for knee extension. For knee flexion, the measurement was only reliable with a muscular pretension of $40 \%$. For MRTD, the results showed a poor reliability.

To achieve the highest available maximum torque in the experimental environment, a minimal $(10 \%)$ is the means of choice. To prevent injuries or measuring errors, a still present pretension seems to be beneficial. The measurement error is reduced to a suitable minimum standard value for older adults. A higher pretension corresponded to a lower maximum rate of torque development. Results showed that the different muscular pretensions did not influence maximum torque in the same way as maximum rate or torque development.

Acknowledgments We thank all persons who participated in the study. Support from the Institute of Movement and Sport Gerontology,
German Sport University Cologne is acknowledged. Additional acknowledgments go to Heinz Mechling, Sabine Eichberg, and Hannah Marston for suggestions, criticism, and corrections.

Conflict of interest Tobias Morat and Peter Preuss declare that they have no conflict of interest. All procedures followed were in accordance with the ethical standards of the responsible committee on human experimentation (institutional and national) and with the Helsinki Declaration of 1975, as revised in 2000 (5). Informed consent was obtained from all patients for being included in the study.

\section{References}

1. Anderson DE, Madigan ML, Nussbaum MA (2007) Maximum voluntary joint torque as a function of joint angle and angular velocity: model development and application to the lower limb. J Biomech 40:3105-3113

2. Arnold CM, Warkentin KD, Chilibeck PD, Magnus CR (2010) The reliability and validity of handheld dynamometry for the measurement of lower-extremity muscle strength in older adults. J Strength Cond Res 24:815-824

3. Atkinson G, Nevill AM (1998) Statistical methods for assessing measurement error (reliability) in variables relevant to sports medicine. Sports Med 26:217-238

4. Blain H, Carrière I, Péninou G, Micallef JP, Colvez A (2006) Reliability of a new instrument for measuring maximum rising strength. Am J Phys Med Rehabil 85:502-508

5. Bobbert MF, Harlaar J (1993) Evaluation of moment-angle curves in isokinetic knee extension. Med Sci Sports Exerc 25:251-259

6. Boes K (2001) Handbuch motorische tests [handbook of motor tests]. Hogrefe, Göttingen, Germany

7. Chambers A, Cham R (2007) Slip-related muscle activation patterns in the stance leg during walking. Gait Posture 25:565-572

8. de Rekeneire N, Visser M, Peila R, Nevitt MC, Cauley JA, Tylavsky FA, Simonsick EM, Harris TB (2003) Is a fall just a fall: correlates of falling in healthy older persons. The health, aging and body composition study. J Am Geriatr Soc 51:841-846

9. Ford-Smith CD, Wyman JF, Elswick RK, Fernandez T (2001) Reliability of stationary dynamometer muscle strength testing in community-dwelling older adults. Arch Phys Med Rehabil 82:11281132

10. Hopkins WG (2000) Measures of reliability in sports medicine and science. Sports Med 30:1-15

11. Hopkins WG, Marshall SW, Batterham AM, Hanin J (2009) Progressive statistics for studies in sports medicine and exercise science. Med Sci Sports Exerc 41:3-13

12. Hughes M, Myers B, Schenkman M (1996) The role of strength in rising from a chair in the functionally impaired elderly. J Biomech 29:1509-1513

13. Kline RB (2005) Beyond significance testing: reforming data analysis methods in behavioural research. American Psychological Association, Washington

14. Kubo K, Ohgo K, Takeishi R, Yoshinaga K, Tsunoda N, Kaneshisa $\mathrm{H}$, Fukunaga $\mathrm{T}$ (2006) Effects of isometric training at different knee angles on the muscle-tendon complex in vivo. Scand J Med Sci Sports 16:159-167

15. Lord SR, Menz HB, Tiedemann A (2003) A physiological profile approach to falls risk assessment and prevention. Phys Ther 83:237-252

16. MacDougall JD, Wenger HA, Green HJ (1991) Physiological testing of the high-performance athlete. Human Kinetics Books, Champaign, IL 
17. Marcora S, Miller MK (2000) The effect of knee angle on the external validity of isometric measures of lower body neuromuscular function. J Sports Sci 18:313-319

18. Marginson V, Eston R (2001) The relationship between torque and joint angle during knee extension in boys and men. J Sports Sci 19:875-880

19. Moreland J, Richardson J, Goldsmith C, Clase C (2004) Muscle weakness and falls in older adults: a systematic review and metaanalysis. J Am Geriatr Soc 52:1121-1129

20. Moxley Scarborough D, Krebs D, Harris BA (1999) Quadriceps muscle strength and dynamic stability in elderly persons. Gait Posture 10:10-20

21. Murray MP, Gardner GM, Mollinger LA, Sepic SB (1980) Strength of isometric and isokinetic contractions: knee muscles of men aged 29 to 86. Phys Ther 60:412-419

22. Pavol MJ, Owings TM, Foley KT, Grabiner MD (2002) Influence of lower extremity strength of healthy older adults on the outcome of an induced trip. J Am Geriatr Soc 50:256-262

23. Phillips WT, Batterham AM, Valenzuela JE, Burkett LN (2004) Reliability of maximal strength testing in older adults. Arch Phys Med Rehabil 85:329-334

24. Pijnappels M, Reeves ND, Maganaris CN, van Dieën JH (2005) Control of support limb muscles in recovery after tripping in young and older subjects. Exp Brain Res 160:326-333

25. Pijnappels M, van der Burg PJCE, Reeves ND, van Dieën J (2008) Identification of elderly fallers by muscle strength measures. Eur J Appl Physiol 102:585-592

26. Ploutz-Snyder LL, Giamis EL (2001) Orientation and familiarization to 1RM strength testing in old and young women. J Strength Cond Res 15:519-523

27. Ploutz-Snyder LL, Manini T, Ploutz-Snyder RJ, Wolf DA (2002) Functionally relevant thresholds of quadriceps femoris strength. J Gerontol A Biol Sci Med Sci 57:B144-B152

28. Rao SS (2005) Prevention of falls in older patients. Am Fam Physician 72:81-88

29. Rubenstein LZ (2006) Falls in older people: epidemiology, risk factors and strategies for prevention. Age Ageing 35(Suppl):ii37-ii41
30. Salminen M, Vahlberg T, Sihvonen S, Piirtola M, Isoaho R, Aarnio P, Kivelä SL (2008) Effects of risk-based multifactorial fall prevention program on maximal isometric muscle strength in communitydwelling aged: a randomized controlled trial. Aging Clin Exp Res 20:487-493

31. Schaubert KL, Bohannon RW (2005) Reliability and validity of three strength measures obtained from community-dwelling elderly persons. J Strength Cond Res 19:717-720

32. Sipilä S, Multanen J, Kallinen M, Era P, Suominen H (1996) Effects of strength and endurance training on isometric muscle strength and walking speed in elderly women. Acta Physiol Scand 156:457-464

33. Symons TB, Vandervoort AA, Rice CL, Overende TJ, Marsh GD (2004) Reliability of isokinetic and isometric knee-extensor force in older women. J Aging Phys Act 12:525-537

34. Tracey BL, Enoka RM (2002) Older adults are less steady during submaximal isometric contractions with the knee extensor muscles. J Appl Physiol 92:1004-1012

35. Viitasalo JT (1982) Effects of muscular pretension on isometric force production. Int J Sports Med 3:149-152

36. Viitasalo JT, Saukkonen S, Komi PV (1980) Reproducibility of measurements of selected neuromuscular performance variables in man. Electromyogr Clin Neurophysiol 20:487-501

37. Wakayama A, Nagano A, Hay D, Fukashiro S (2005) Effects of pretension on work and power output of the muscle-tendon complex in dynamic elbow flexion. Eur J Appl Physiol 94:339-347

38. Welsch MA, Williams PA, Pollock ML, Graves JE, Foster DN, Fulton MN (1998) Quantification of full-range-of-motion unilateral and bilateral knee flexion and extension torque ratios. Arch Phys Med Rehabil 79:971-978

39. Willardson JM (2004) Sarcopenia and exercise: mechanisms, interactions, and application of research findings. Strength Cond $\mathrm{J}$ 26:26-31

40. Yoon TS, Park DS, Kang SW, Chun S, Shin JS (1991) Isometric and isokinetic torque curves at the knee joint. Yonsei Med J 32:33-43

41. Yu B, Gabriel D, Noble L, An KN (1999) Estimate of the optimum cutoff frequency for the Butterworth low-pass digital filter. J Appl Biomech 15:318-329 